\title{
Abraham Goldberg
}

\author{
Expert on porphyria
}

Abe Goldberg was a world expert on the porphyrias. In a career spanning over 50 years he made huge strides in the understanding and treatment of the disease, and wrote the definitive textbook on the subject. He chaired the Committee on Safety of Medicines for six years, and did some scholarly work in modern history. He also, in a landmark paper with colleagues in 1967, traced a cluster of mentally retarded children in Glasgow to the storage of drinking water in lead lined tanks.

Abe Goldberg was born in Edinburgh; his parents, both from eastern Europe, worked in the garment trade. They were active members of the Edinburgh Jewish community, though not particularly observant. Outstanding at his junior school, Abe lost six months' education because of rheumatic fever, which formed the basis of his decision to enter medicine. He won a scholarship to George Herriot's School, where he won the literary and public speaking prizes. He was awarded the Crichton bursary to study medicine at Edinburgh, graduating in 1946.

He was called up for national service shortly afterwards, serving in the Royal Army Medical Corps, mainly in Egypt. This coincided with the establishment of the state of Israel, which was a lifelong interest.

Returning to civilian life along with many other doctors, he had-like many of themdifficulty in finding a house job. After six months at Withington Hospital, Manchester, he went to the children's hospital in Edinburgh, which was, he said, the most painful and difficult job he had to do.

By then he realised that he wanted an academic career, and obtained a two year Nuffield fellowship in chemical pathology at University College Hospital in London in 1952, where he learnt laboratory techniques and research methods. He was then awarded a two year Eli Lilly travelling fellowship in medicine to Utah University. He enjoyed his stay but was alarmed at the inequalities in health care.

He returned to University College Hospital but was soon recruited back to Scot-

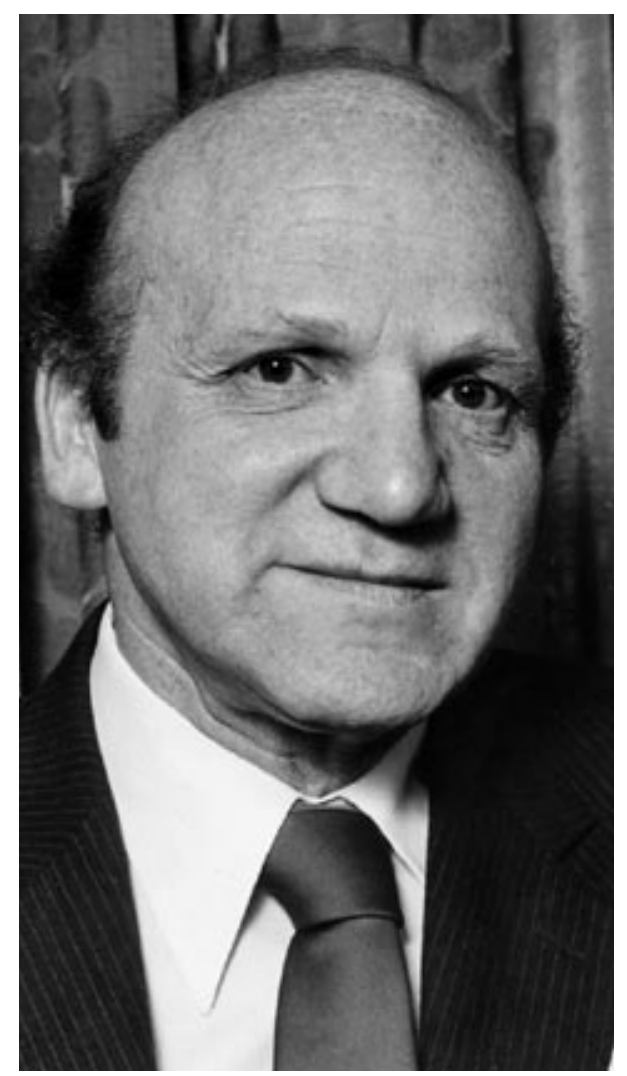

became research associate and then professorial research fellow in modern history. He liked to give a historical perspective in his lectures and on one occasion a student complained, "Doctor, can ye no just gie us the facts."

He served on the Medical Research Council, the Scottish Home and Health Department, the Chief Scientist's organisation, and Glasgow University's grants committee. From 1980 to 1986 he headed the Committee on Safety of Medicines, where he devised a quick reference wheel of drug interactions for general practitioners. He was on the editorial board of the British National Formulary and the Scottish Medical Journal. He was the founding president of the Royal College of Physician's faculty of pharmaceutical medicine. In 1974 he established the West of Scotland Alcohol Research Group.

He wrote a bedside teaching manual for medical students, a series of clinical slides with tapes, and a paper on the future of Scottish medical education, and he coauthored Disorders of Porphyrin Metabolism (1987), Diseases of Porphyrin Metabolism (1962), Recent Advances in Haematology (1971), and Pharmaceutical Medicine and the Law (1991). He won many prizes and gave many "name" lectures.

Cervical and lumbar spondylosis limited his activities in later life, and in the 1980s he stood down as elected president of the College of Physicians and Surgeons of Glasgow as it would have entailed too much travelling. In 2006 he barely survived a serious stroke and spent his last four months in a care home.

Abe Goldberg met Clarice Cussin early in 1957. They had a whirlwind romance, becoming engaged after a fortnight and marrying that September. He was buried on what would have been his 50th wedding anniversary. His wife and three children survive him.

\section{Caroline Richmond}

Sir Abraham Goldberg, regius professor of medicine, Glasgow (b 1923; q Edinburgh 1946; KBE, MD, DSc, FRCP, FRCPEd, FRCPGlas, FRSE), died from a heart attack on 1 September 2007. 